\title{
Intra- and interhemispheric variability of SST and the hydrological cycle over the last 4 Myr
}

\section{Trins, Austria, 30 May-2 June 2007}

\section{Michael Sarnthein ${ }^{1}$ and workshop participants}

IInstitute for Geosciences, University of Kiel, Germany; ms@gpi.uni-kiel.de

This lively workshop addressed recent progress in establishing past sea surface temperature (SST) patterns, with new advances in both recording continental humidity changes and modeling past variations of the hydrological cycle. Exciting insights were presented on changes in meridional (L. Stott) and zonal (L. Vidal; L. Peterson) Atlantic moisture gradients and transport on stadial-to-interstadial timescales (Fig. 1). New centennial- to decadalscale records revealed extreme Holocene variations in the African (S. Weldeab) and Indian (A. Sinha) summer monsoons. These were, in part, coeval with short-term climate changes in Europe, such as temperature-controlled Alpine glacier advances ( $\mathrm{K}$. Nicolussi). However, reliable links between marine and continental records will require new standards in age control, with uncertainties better than $300 \mathrm{yr}$.

During the workshop, participants split into interactive theme groups to develop hypotheses, recommendations and strategies related to the following four major (paleo-) climatic issues:

\section{A) Hadley vs Walker Circulation, Atlantic- Pacific Zonal vs Meridional ITCZ Shifts}

Andre Paul and Lowell Stott (Chairs)

This group discussed the role of watervapor transport, jets and Intertropical Convergence Zone (ITCZ) migrations. Short- and long-term variability of the inter-ocean exchange of water vapor were identified as key objectives, particularly in view of competing ideas on their effect on the oceans' salt balance (including analyses and re-evaluation of meteorological and oceanographic data sets, e.g., from the World Ocean Circulation Experiment (WOCE)).

Data-model comparison is required to test whether:

1) Atmospheric moisture transport across Central America controls the Pacific and Atlantic salinity contrast and modern thermohaline circulation (THC) (Fig. 1).

2) The amplitude of glacial/interglacial and stadial/interstadial changes reconstructed on either side of the Central American Isthmus can be reconciled with changes in zonal moisture transport.

3) Changes in monsoon are related to changes in atmospheric $\mathrm{pCO}_{2}$.

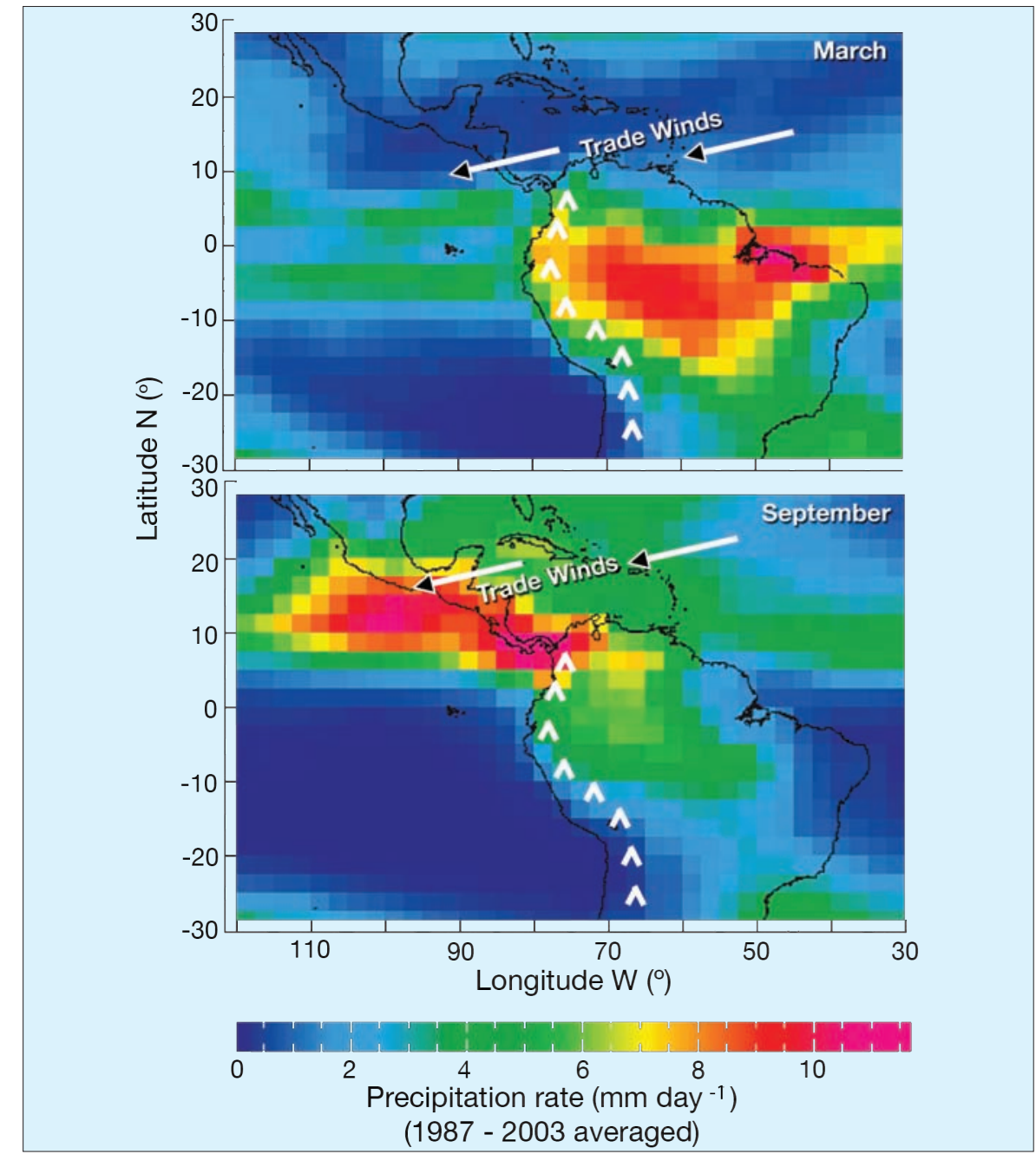

Figure 1: Wind-driven zonal atmospheric water transport, depicted by averaged precipitation rates over Middle and South America for Mar. and Sept. between 1987-2003 AD (modified from Leduc et al., 2007). Enhanced Sept. precipitation in the East Pacific reflects major freshwater export from the equatorial Atlantic that may have strongly varied from interstadial to stadial times, and in turn led to major variations in sea-surface salinity and Atlantic meridional overturning circulation. The Andes (hill symbols) keep freshwater in the Amazon basin during March.

Future studies should focus on target regions that are:

1) Critical for atmospheric dynamics, based on their potential as source (e.g., the tropical ocean), sink, or pathway (e.g., Isthmus of Panama) of atmospheric moisture.

2) Highly sensitive to climate change (producing large and regionally representative signals).

3) Relevant to large human populations.

B) Phasing of Monsoon Precipitation in Africa, India, and East Asia/West Pacific

Dominik Fleitmann and Ralph Schneider (Chairs)

Group B discussed time-transgressive shifts in rainfall and near-shore sea-surface salinities throughout the Early Holocene climate optimum. They also debated the links between precipitation and factors such as tropical Indian SST, the Atlantic Dipole and tropical zonal seesaw. To examine the phasing of such changes, it was felt that chronologies of marine and terrestrial records should be developed separately, to enable reliable and independent comparison of local precipitation and temperature records. Tree rings and speleothems were also considered the superior archives for developing regional master chronologies, as age models deduced from marine records are based on multiple timescales and require initial tuning to Greenland and Antarctic ice-core timescales. Comparison of $\delta^{18} \mathrm{O}$ records from fluid inclusions in spe- 
leothems with nearby planktic $\delta^{18} \mathrm{O}$ records may serve as a novel correlation tool.

Future strategies should include the initiation of new research networks to establish regionally integrated information on monsoon changes, such as tropical ice cores, and include East Pacific regions that are influenced by both monsoon and westerlies.

\section{C) Hemispheric and Interhemispheric Teleconnections}

Mark Maslin and Larry Peterson (Chairs) This group proposed five questions for testing:

1) Do tropical hydrology and ITCZ shifts respond consistently to changing highlatitude temperatures and meridional temperature gradients?

2) Do tropical warm-pool temperatures control the export of water vapor from low to higher latitudes, and what are the climatic feedbacks between these regions?

3) Are methane concentrations in ice cores indicative of methane release in tropical or high-latitude wetlands, and are they an important amplifier of hydrological changes?
4) ENSO as a potential forcing mechanism of past monsoonal intensity has only been recorded in varved sediments off Pakistan. Can a clear ENSO signal also be identified in proxy records from other monsoon regions?

5) High-latitude climate responds to enhanced dust transport due to changes in tropical wetness and aridity, yet what are the actual effects of high dust supply on climate?

\section{D) Human-scale events in the} Hydrological Cycle over the last $20 \mathrm{kyr}$

Ashish Sinha and David Anderson (Chairs) Group D focused on abrupt climate shifts and magnitudes of change that can be compared to historical records. Periods that appear particularly important include the last $2 \mathrm{kyr}$ and the $8.2 \mathrm{kyr}$ cooling event, implying that the following studies are required:

1) The extent to which climatic changes over the last $2 \mathrm{kyr}$-termed in Europe the "Little Ice Age", the Medieval and Roman Warm Periods-are connected to large-scale patterns of climate variability. Are these evident in worldwide anomalies of SST, droughts, and floods? To what extent are coeval variations in tropical monsoons connected to other tropical processes such as the Indonesian Throughflow, Walker, and Hadley circulations?

2) The role of tropical SST in driving hydrologic variability throughout the extratropics appears evident in model-based studies and instrumental records. Yet, long-term trends in this ocean-climate linkage are poorly known. New proxy records of the last $2 \mathrm{kyr}$ may help to assess the long-term influence of ocean SST patterns on hydrologic changes in remote regions.

This workshop demonstrated the merit of this relatively novel approach in addressing past variations in the hydrological cycle as a result of changes in ocean circulation. The presented results and subsequent discussions suggest that integration of paleoceanography and land paleoclimatology will yield dramatic progress in our understanding of the oceans' role in hydrologic change on many timescales.

\section{References}

Leduc, G., Vida, L., Tachikawa, K., Rostek, F., Sonzogni, C., Beaufort, L. and Bard, E., 2007: Moisture transport across Central America as a positive feedback on abrupt climatic changes, Nature, $\mathbf{4 4 5}$ as a positive

\title{
3rd Alexander von Humboldt International Conference: East Asian Monsoon, past, present and future
}

\section{Beijing, China, 9-11 August 2007}

\author{
André Berger ${ }^{1}$, Z. Ding ${ }^{2}$, Z. Guo ${ }^{2}$ and P. Fabian ${ }^{3}$ \\ 'Institute of Astronomy and Geophysics G. Lemaître, Catholic University of Louvain, Belgium; berger@astr.ucl.ac.be; \\ ${ }^{2}$ Institute of Geology and Geophysics, Chinese Academy of Sciences, Beijing, China; ${ }^{3}$ Technical University of Munich, Germany
}

The instrumental period of the meteorological record is too short to capture the full variability of the climate system and, in particular, to visualize the type of climate that is predicted to occur over the next decades and centuries. It is therefore, important to reconstruct past climates and understand past climatic variations. Marine deep-sea cores and ice cores have and will continue to contribute to our understanding. Land records also contribute significantly, particularly at the regional scale.

The Third European Geosciences Union (EGU) Alexander von Humboldt International Conference was devoted to the "East Asian Monsoon, Past, Present and Future". Both records of the past and present-day observations and model experiments were reviewed, to better understand the mechanisms driving its behavior and to allow for better predictions of it and its impacts.
60 oral presentations and 26 posters gave an excellent overview of the EAM and its evolution over the last $25 \mathrm{Myr}$, gathering important records and modeling results. The abstracts of the papers and posters are available in "Program in details" at www. conferencenet.org/conference/3rdAVH/ $\mathrm{html} /$ whatnew.htm, among them some scientific results to illustrate the EAM behavior at the different timescales covered during the meeting.

J. Guiot presented information on the mechanistic vegetation models that clarify the minimum climatic changes required to produce the vegetation shifts observed in paleodata.

The impact of the uplift of the Tibetan Plateau (TP) and the Rockies (RC) on Asian summer and winter monsoon climate was investigated, using both data and models for the last tens of million of years. Using the Meteorological Research Institue-coupled general circulation model, T. Yasunari

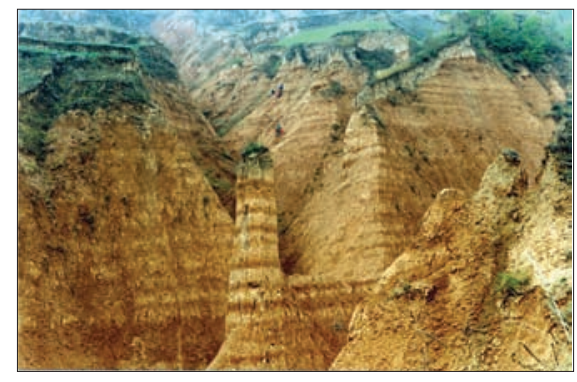

Figure 1: Field photo showing the alternation of loess (yellow layers) and paleosols (red-brown layers) in Miocene loess-soil sequences from the Chinese Loess Plateau, Gansu Province (courtesy of Zhengtang Guo, IGGCAS Beijing).

showed that, the zonal asymmetry of SSTs in the subtropical North Pacific is emphasized by the presence of both TP and RC, and enhancement of the Asian summer monsoon climate is likely to appear as an overall effect of the atmosphere-ocean interactions principally in the Pacific but also secondarily in the North Atlantic.

Z. Guo and Z. An both showed that the climate pattern in Asia experienced 